\title{
THE PSYCHOLOGICAL RESEARCH OF THE DOMINANT CONFIGURATION MODELS OF MARITAL RELATIONSHIPS OF A WOMEN WITH NEUROTIC DISORDERS
}

DOI: 10.36740/WLek202003128

\author{
Kira V. Sedykh' ${ }^{1}$, Nadiia M. Myshko' ${ }^{1}$, Tamila V. Zozul' \\ 'POLTAVA V.G. KOROLENKO NATIONAL PEDAGOGICAL UNIVERSITY, POLTAVA, UKRAINE \\ 2PRIVATE HIGHER EDUCATIONAL ESTABLISHMENT «ACADEMICIAN YURIY BUGAY INTERNATIONAL SCIENTIFIC AND TECHNICAL UNIVERSITY» \\ POLTAVA, UKRAINE
}

\begin{abstract}
The aim: To study the psychological peculiarities of relationships in families of women with neurotic disorders.

Materials and methods: 30 women who received treatment in the neurotic unit of the A.F. Maltsev Poltava Regional Clinical Psychiatric Hospital and 30 mentally healthy women have been examined. In the research the authors used a complex of interrelated and complementary general scientific and specific methods based on the systematic approach. Results: There was a tendency for following types of marital interactions: dependent $-58 \%$ of couples, intermediate $-35 \%$ of couples. The emotionally-metaphorical type of interpreting life events is inherent for $89 \%$ of women with neurotic disorders. Studying the types of relationships with a husbands demonstrated that women with neurotic disorders perform 'the role of victim' $-30 \%(1,7689)$ and 'the role of 'burden" $-40 \%(1,7689)$ in their relationships.

Conclusions: The types of relationships with a partner of women with neurotic disorders are partly determined by the specifics of early parenting experiences.
\end{abstract}

KEY WORDS: neurotic disorders, relationship narratives, family narrative, dominant configuration in relationships, CCRT

Wiad Lek. 2020;73(3):551-554

\section{INTRODUCTION}

Neurotic disorders rank among the most prevalent mental illnesses [1,2]. The study of the dominant configuration of relationships of women with neurotic disorders is very important in this sense. As the dominant configuration is the subjective relations of the individual, the formation of which is carried out under the influence of appropriate methods of perception of the environment, adequate or inadequate reactions to the environment, normal or pathological forms of a psychological defense. These are the keys to relationship with oneself, relationships with other people and relations with the environment.

These patterns originate in early childhood experiences, more precisely, in examples of family interactions that were often repeated. Such relationship models are effectively studied using the RAP interview method.

\section{THE AIM}

To find out and study the behaviour models in families of women with neurotic disorders.

\section{MATERIALS AND METHODS}

30 women who received treatment in the neurotic unit of the A.F. Maltsev Poltava Regional Clinical Psychiatric Hospital (the patients - the experimental group) and 30 mentally healthy women (the respondents - the control group; mean age of all women 40) have been examined. The women participated in a longitudinal study over a 1year period.

During the research, we used a complex of interrelated and complementary general scientific and specific methods based on the systematic approach. Such as the family sociogram, questionnaires and the Relationship Anecdotes Paradigm (RAP) interview.

Sociometric techniques are methods for observing, measuring and modifying social interactions, including family interactions. Sociometric techniques are well suited to couple and family therapy because of their effectiveness in vividly portraying each person's place in the system, the member's patterns of interaction and their feelings about it [3]. We used the family sociogram for charting preferences and choices in family relationships. The respondents were presented a handout with a circle with a diameter of 110 $\mathrm{mm}$ drawn on it. Then, the respondents were asked to draw themselves and their family in a circle. We analyzed the next criteria: the number of family members in the circle area; the magnitude of the circles; the arrangement of circles relative to each other; the distance between them.

The questionnaires method was used for researching the peculiarities of family relationships. It allowed to implement a subjective approach to psychodiagnosis and increase our understanding of respondents' family behaviors. 
The RAP interview method is a purposeful conversation with the client about his or her relationship with others [4]. The respondents were asked to tell about specific cases of their interactions with others (for example, meeting, telephone conversation) that had taken place in the past. The cases would be specific, validated examples, and should not be limited to summarize the 'typical' situation of relationships with significant others. Since the materials of our research were transcripts of special interviews with patients and respondents, the relationship episodes were highlighted by us as particular stories that reflected relationships with significant others. The relationship episodes include three components, such as: (a) wishes, needs, or intentions expressed by the subject (wishes); (b) expected or actual responses from others (ROs); and (c) responses of self(RSs); i.e., the patient's own emotional, behavioral, or symptomatic responses to responses of others [5]. Then components received from all processed episodes were analyzed, reformulated in conformity with CCRT and statistically calculated.

\section{RESULTS AND DISCUSSION}

In the present study, the family sociogram found out the following types of interaction in the studied pairs of women with neurotic disorders: dependent $-58 \%$ couples, intermediate- $35 \%$ couples, harmonious $-7 \%$ couples.

The most popular type of family interaction among the researchers is dependent. Dependent pattern of interaction is characterized by the following features: excess value relation to family members with fixing family relationships, unrealistic, uncritical expectation of unconditionally positive attitude on the part of family members to each other, with the refusal of an opportunity to be themselves; conscious fear of being abandoned, which reduces negative feelings about objects and forces any victims to preserve relationships; unconscious fear of intimacy between the couple that inhibits sex appetence in physical intimacy, the desire to be with another person and at the same time fear to be absorbed by him.

For families with such type of relationship imbalance in the hierarchy between parent and child subsystems are inherent. This option can be represented as a wheel where the spokes are children, and axis is the mother, who is responsible for every little thing that happens to children without the transference of some responsibilities to them. Such mother seems to be overloaded with her permanent tasks. Children always ask something their mother, show her what they have done, ask her to arrange conflicts and try to consult everything before doing something. Such structure is typical for unshared power.

Intermediate pattern of interaction that is inherent in 35\% of the studied couples is characterized by the following features: configuration of relationships is intermediate, communication of family members is realized through a third person (for example, child) or through a common theme (for example, family business or family member illness), thus, communication does not occur directly, and not all members of the nuclear family are directly related. Married couples with this type of interaction cannot discuss openly their problems and the tension in their relationships. It means, the regulator of family relationships is beyond area of the family, it's in the expanded system of relations.

The harmonious pattern of interaction, which is least characteristic of the studied couples, is characterized by the following features: relationships in nuclear families are strong and medium, the emotional distance between the members of the nuclear family is close; boundary of the nuclear family is normal, it means that there is sufficient exchange with the environment, there is a good balance between 'take' and 'give'; with enough intense emotional ties, there is enough autonomy for each family member and children. For example, the spouses have common friends and common interests, but they have their own friends and interests as well. Due to this a common and a private area are saved. Responsibilities are shared, responsibilities are delegated. These families also experience the drift between the parental 'control' and 'risk' for their children's autonomy.

The next step in our study was to analyze the way the patients experience and interpret their own lives, through the RAP interview method.

O. Sapogova [6] suggested a formal analysis of narratives and distinguished the following methods of organizing narratives about events:

- The ascertaining emotionless method (the descriptive meth$o d$ ) is a schematic list of events, statement of facts without their analysis, emotional impressions and reflections; the superficial narrative;

- The emotionally metaphorical method (the performative method) is a description of 'cases' (lyrical, comic, tragic, dramatic) that have a special meaning and significance; narratives are accompanied with evaluations, questions and etc.;

- The instructive method (the didactic method) the story is composed or saturated with instruction, edification, instructive statements as an 'example' of a courageous or other, worthy imitation of life; the description consists of many conclusions and moralizing statements;

- The analytical and teleological method (the entimematic method) is a description of purposeful movement towards the goal with analysis and explanation of the motivation of own actions or actions of other people, as a confrontation with obstacles;

- The symbolic method (the allusive method) is a description of each life event as mystical that has the secret meaning, influence on the destiny, on other people, on the world in general.

This study found that significant differences exist between the study groups. In particular, the most prevalent type of interpretation of life experience among control group is the ascertaining emotionless method $-65 \%(p \leq 0,05)$. The respondents are characterized by emotionless, impartial, and the most objective attitude to life events. They try to build their attitude to life as objectively as possible, in contrast to the experimental group under study, where the emotionally metaphorical method interpretation is the leading type of narratives $-89 \%(\mathrm{p} \leq 0,01)$. 
The emotionally-metaphorical type of interpreting life events is inherent for $89 \%$ of women with neurotic disorders. Thus, patients are inclined for symbolic interpretation of life events, using metaphorical statements in their description and moving away from the objective evaluation of life events.

Other ways of interpreting life events among the groups are not well expressed. The instructive method was found in $6 \%$ of women of the experimental group and in $15 \%$ of the control group. It means, the interpreting of life events by the instructive method is little inherent in patients.

The analytical and teleological method was revealed in $20 \%$ of women of the control group and 5\% of the experimental group. These results suggest that both patients and respondents are not inclined to a detailed and balanced analysis of life events and their impact on the present, but respondents have a certain tendency for that.

So, this part of research demonstrated that patients are really more focused on the emotional interpretation of the events of their lives and their uncritical perception. But the respondents are more focused on the schematic list of events of their lives without emotional impressions and building narratives on that basis.

Studying the types of relationships with a husbands demonstrated that women with neurotic disorders perform the role of victim - 30\% $(1,7689)$ and the role of 'burden' - 40\% $(1,7689)$ (the dependent interaction) in their relationships. That is, most of women feel addicted to their husbands, relying on husbands' opinion in all matters and exhibiting psychological immaturity; or consider themselves victims of their husbands. To a lesser extent, patients are also characterized by such types of relationships as 'aggressive type' - 13\% and 'conflict with the desire to distance' - 13,7\%. The least popular types of relationships with a partner are 'harmonious' - $0 \%$ (completely alien to women with neurotic disorders), and 'conflict with a desire to become closer' (3,3\%). So, women with neurotic disorders are inherent neither harmonious relationships nor the desire for psychological closeness with a husband.

The relationships with husbands have emotional primitive nature in the experimental group as opposed to the control group where the high rates of positive relationships (13.8489) indicate their high emotional color.

The qualitative analysis of the interview within the CCRT results shows that the reactions of other people usually are described by the experimental group more negatively than their own reactions $-80 \%$.

In general, the results of the RAP interview indicate that the most often CCRT occurred in patients are the desire for love, the social rejections and their own disappointment reaction. A low level of the desire 'to have understanding with others', an increased level of dislike for others and feelings of hopelessness and helplessness were revealed in over half of the patients of the experimental group.

The patients tend to the typical patterns in relationships that are characterized by a low desire to get help from others and a less desire to communicate with others to improve their own well-being. Women with neurotic disorders are characterized by alexithymia and anhedonia in relationships. So, the behaviour patterns specific to alexithymia had been identified: the need to be kind to others is reduced; perceiving others as willing to help; low response to the needs of others and conflict with somatic symptoms. Therefore, women with neurotic disorders have low expectations about other people and have no motivation to excuse the expectations of others. These results are fundamentally different from results of the control group.

Based on the narrative analysis, we have hypothesized that the characteristics of relationships in the parental families of the women with neurotic disorders are the basis for creating models of relationships with their own husbands. The peculiarities of the influence of relationships with parents on the marital interaction of the investigated have been determined also using the CCRT method. From the point of view of psychoanalysis, such relationships are the result of the relationship of personal and individual desires, fears and protective strategies, on the one hand, and the reactions and models of partners, on the other [7].

This study had found that patients demonstrate all types of relationships (conflict with the desire to distance, conflict with the desire to become closer, the role of victim, aggressive type, dependent type) with their parents, except the harmonious ones. Each type of relationships is inherent to $20 \%$ of experimental group. $20 \%$ patients are characterized by such type of relationships as 'the conflict with the desire to become closer' and $20 \%$ patients as - 'the conflict with the desire to distance'. The parent-child relationships of women with neurotic disorders are conflictual, but in the first subgroup due to excessive distance (in this case, women want to become closer to their parents) and in the second subgroup due to excessive parental involvement in children's lives (in this case, women want to set the family boundaries and to be separated from their parents). The dependent type of relationships with their parents is inherent for $20 \%$ of the patients. That is, they felt a total dependence on parents which caused them to manifest of psychological immaturity, dependence etc. $20 \%$ of those who were interviewed indicated that they performed "the role of victim" in the parent-child relationships. They felt victimized and developed a proper behavior (behaving as if all family troubles had arisen because of their presence in the family, periodically manipulating parents). Also 1/5 part of experimental group is characterized by the aggressive type of relationships with their parents: patients felt constant reproaches from their parents, psychological distance from the parents and had been physical abused in childhood.

Thus, in part of patients their autonomy was maintained in the parental family because of their parents' indifference to them. Relationships were maintained through the control or over-involvement of parents in the child's life. This formed an immature relationship model dominated by interconnections, interdependence, and fear of intimacy.

The passive desires of patients ('I want to be loved and understood') dominate in episodes of relationships with their parents (mother, father) - 81\%; whereas on the contrary the active desires ('I want to love, I want to become 
to closer him') dominate in episodes of relationships with husbands $-70 \%$. The father is most often described as dominant $-84 \%$, while husband - as controlling $-68 \%$. Other women are more often characterized as strong and not ready for understanding - 75\%. But, in general, all patients feel respect and love of their parents more often than the same of their husbands - 91\%. Also patients have less control over themselves in the relationships with husbands.

The types of relationships with a partner of women with neurotic disorders are partly determined by the specifics of early childhood experiences. At the same time, the share of positive reactions in relations with husbands exceeds the share of positive reactions towards parents in both groups: the experimental group - $85 \%$, the control group - $60 \%$.

The results of our study showed that patients have the ability to change cliché-shaped relationships models; and have the ability to form new behavioral patterns in a current relationship. Patients can use the positive experience of the relationship as a positive identification and a positive social reinforcement. Also the positive experience of the relationships can be used by psychiatrists, psychologists, psychotherapists to help determine patients' psychological resources; to evaluate patients' ability 'to think out of the box', to perceive and describe the current relationships differentially.

\section{CONCLUSIONS}

As a result, we have demonstrated that the dominant configuration actually has powerful influence to interaction not only with parents but interaction with other significant men and women for patients as well. Along with this, in the episodes of relationships with husbands' other categories and models of relationships that differ from parent-child come to the fore both of the patients and the respondents. Despite overwhelmingly negative relationships with parents and women's inclination to transfer these relationships to other people, women could change cliché-shaped relationship models and have a positive relationship with other significant partners. This indicates important interpersonal resources of psychotherapeutic patients and clients, meaning that they are more flexible than they seem, and capable of creating new types of relationships and experiences that they ever had with their parents. Besides psychotherapeutic patients and clients can enjoy the support of other people, if not completely, then not infrequently from close people and important social environment.

\section{REFERENCES}

1. Anxiety disorders. In: Diagnostic and Statistical Manual of Mental Disorders, 4th edn. Washington, DC: American Psychiatric Association; 2000; p. 429-484.
2. Barlow D.H. The experience of anxiety: shadow of intelligence or specter of death? In: Barlow D.H. (ed). Anxiety and its disorders: The Nature and Treatment of Anxiety and Panic, 2nd edn. Guilford Press, New-York; 2002, p. 1-36.

3. Sherman R., Fredman N. Handbook of structured techniques in marriage and family therapy. New York: Brunner/Mazel; 1987, p. 148-158.

4. Abalakina M.A. Mezhlichnostnoe vosprijatie i dinamika predbrachnyh otnoshenij [Interpersonal Perception and the Dynamics of Premarital Relations]. (Ph. D. diss.). Moscov; 1987, 203 p. (Ru)

5. Luborsky L. The Relationship Anecdotes Paradigm (RAP) Interview. In: Luborsky L. \& Crits-Christoph P. eds. Understanding transference: The Core Conflictual Relationship Theme Method. New York: Basic Books; 1990, p. 102-116.

6. Sapogova E.E. Avtobiograficheskij narrativ v kontekste kul'turnoistoricheskoj psihologii [The autobiographic narrative in the context of cultural-historical psychology]. Cultural-Historical Psychology. 2005; 2: 63-74. (Ru)

7. Zozul T.V. Psihologichni osoblivosti formuvannja stosunkiv podruzhnih par iz velikoju rizniceju u vici [The psychological features of the formation of relationships in a marriage couples with a significant age difference]: (Ph. D. diss.). Harkiv; 2016, 200p. (Ua)

Article is written within the research topic of the Psychology Department of the Poltava V.G. Korolenko National Pedagogical University «Synergistic approach to psychological processes in systems of different level of organization" (state registration number 0117U003062).

\section{ORCID and contributionship:}

Kira V. Sedykh - 0000-0003-3528-7569 B, C, D, F

Nadiia M. Myshko - 0000-0002-6354-051X B, C, D, E

Tamila V. Zozul - 0000-0003-0097-7113 A, B, D, E

\section{Conflict of interest:}

The Authors declare no conflict of interest.

\section{CORRESPONDING AUTHOR \\ Tamila V. Zozul}

Brativ Shemetiv 19, ap. 40

Poltava, 36039, Ukraine

tel: +380993514935

e-mail: tamilazozul@gmail.com

Received: 17.01 .2020

Accepted: 05.03 .2020

A - Work concept and design, B - Data collection and analysis, C - Responsibility for statistical analysis, D-Writing the article, $\mathbf{E}$-Critical review, $\mathbf{F}$ - Final approval of the article 